\title{
On the effects of using $\mathrm{CO}_{2}$ and $\mathrm{F}_{2}$ lasers to modify the wettability of a polymeric biomaterial.
}

\author{
D. G. Waugh ${ }^{1}$, J. Lawrence ${ }^{1}$, C. D. Walton ${ }^{2}$ and R. B. Zakaria ${ }^{2}$ \\ ${ }^{1}$ Wolfson School of Mechanical and Manufacturing Engineering, Loughborough University, \\ Leicestershire, LE11 3TU, UK \\ ${ }^{2}$ Department of Physical Sciences, Physics, University of Hull, Kingston-Upon-Hull, HU6 7RX, UK
}

\author{
Corresponding Author: \\ Mr. David G. Waugh \\ Wolfson School of Mechanical and Manufacturing Engineering \\ Loughborough University \\ Loughborough \\ LE11 3TU, UK \\ Tel: 01509227593 \\ Fax: 01509227648 \\ Email: D.G.Waugh@lboro.ac.uk
}




\section{1 - Abstract}

Enhancement of the surface properties of a material by means of laser radiation has been amply demonstrated previously. In this work a comparative study for the surface modification of nylon 6,6 has been conducted in order to vary the wettability characteristics using $\mathrm{CO}_{2}$ and excimer lasers. This was done by producing $50 \mu \mathrm{m}$ spaced (with depths between 1 and $10 \mu \mathrm{m}$ ) trench-like patterns using various laser parameters such as varying the laser power for the $\mathrm{CO}_{2}$ laser and number of pulses for the excimer laser. Topographical changes were analysed using optical microscopy and white light interferometry which indicated that both laser systems can be implemented for modifying the topography of nylon 6,6. Variations in the surface chemistry were evaluated using energy-dispersive X-ray spectroscopy and X-ray photoelectron spectroscopy analysis and showed that the $\mathrm{O}_{2}$ increased by up to $1.5 \%$ At. and decreased by up to $1.6 \%$ At. for the $\mathrm{CO}_{2}$ and $\mathrm{F}_{2}$ laser patterned samples, respectively. Modification of the wettability characteristics was quantified by measuring the advancing contact angle, which was found to increase in all instances for both laser systems. Emery paper roughened samples were also analysed in the same manner to determine that the topographical pattern played a major role in the wettability characteristics of nylon 6,6. From this, it is proposed that the increase in contact angle for the laser processed samples is due to a mixed intermediate state wetting regime owed to the periodic surface roughness brought about by the laser induced trench-like topographical patterns.

Keywords: $\mathrm{CO}_{2}$ laser, $\mathrm{F}_{2}$ laser, nylon 6,6, wettability, contact angle.

\section{2 - Introduction}

The study of wettability has been a major focal point for many researchers and has been applied to a wide range of applications such as biomedical [1-4], coating technologies [5,6] and adhesion [7-9]. As the interface between a solid and liquid can be very complex it is necessary to account for the wetting regime that takes place. Two of the most common wetting regimes is that of Wenzel and Cassie-Baxter. In most instances it is seen that for hydrophilic surfaces (surfaces which provide contact angles of less than $90^{\circ}$ ) the Wenzel wetting regime dominates in which the whole of the liquid wets the surface. For hydrophobic surfaces (contact angles greater than $90^{\circ}$ ) the wetting regime tends to be that of Cassie-Baxter in which air-gaps are formed between the liquid-solid interface. However, in some cases it has been seen that it may be possible for a hydrophilic surface to give rise to some form of Cassie-Baxter wetting or CassieBaxter/Wenzel mixed intermediate wetting regime owed to the roughness and topographical pattern on the surface $[10,11]$. In this instance it is seen in some cases that increasing the surface roughness, through the patterning of a surface, can give rise to an increase in contact angle for hydrophilic materials. On the 
other hand, it has also been observed that in general, when the surface energy and its components are a dominant factor, the contact angle is a decreasing function of the polar component of the surface [12].

Leading on from this it can be seen that it is advantageous for these various applications to devise a repeatable technique which would allow material surfaces to be modified in order to optimize that surface for the required application. Numerous methods have been developed to produce these modified surfaces. Some of these methods are radiation grafting [13], plasma surface modification [14,15] and using various coatings [6]. Laser surface modification [16,17] is another process which has the ability to modify both the topography and surface chemistry of a material with negligible affect to the bulk properties. In comparison to other competing techniques lasers offer a number of benefits such as relative cleanliness, accurate processing, non-contact and flexible processing.

In terms of laser beam interactions with materials, the way a material responds to the incident laser is highly dependant upon a number of parameters. Specific to polymers, IR lasers give rise to resonant coupling in the form of bond and lattice vibrations allowing for the processing to be thermolytical. This is due to the fact that the photon is only weakly absorbed by the polymer, with the energy that has been absorbed being distributed to vibrational modes [18]. Whereas, UV lasers tend to give rise to the absorption of the light through electronic excitation which is often within delocalized electron configurations. In consequence polymers can have broad absorption features and directly break the polymer bonds as a result of the high photon energy [19]. With most lasers it is seen that the smallest possible features that can be achieved are on the micron scale; however, nano-structures have been achieved using a laser emitting at a wavelength of $157 \mathrm{~nm}$ [20]. These variations in micro and nanostructured topographies have been seen to have a major influence on the characteristic contact angle that arises from the processing [21,22]. In addition, it has also been observed that in some instances the surface chemistry dominates the wettability characteristics of a material, such as through the work of Kietzig et al. [23] which observed that for metallic surfaces the carbon content appears to have a considerable influence on the wettability characteristics.

Lasers can be employed to produce variations in surface characteristics which can induce a change in contact angle, surface energy and surface chemistry. In fact for some applications such as those within the biomedical field it has been stated that the characteristic wettability properties may be the driving force in determining how certain cells will react to a material [12]. The role of wettability in biomaterials science has been one of the most interesting subject areas in biomaterials surface science for a number of years and has allowed many to endeavor to determine the complex links between surface wetting and bioactivity [24]. This is owed to the fact that the common theme emanating from past work is that in 
many applications it is seen that the bulk properties of a biomaterial are decided upon such that the surface properties are compromised [12,25]. Through the available literature it can be seen that extensive research is now being carried out regarding this in the attempt to link wettability and bioactivity of materials $[3,4]$.

Throughout the literature it is seen that a correlation between the laser wavelengths and wettability has not been fully established. As such, this paper is the beginning of a long-term study into the variation of wettability and the parameters which affect it by using lasers with differing wavelengths. For this research $\mathrm{CO}_{2}$ and excimer lasers have been employed and compared to produce surface variations in nylon 6,6 along with the wettability characteristics being quantified in terms of advancing contact angle, apparent surface energies and surface $\mathrm{O}_{2}$ content.

\section{3 - Experimental Procedures}

\section{$3.1-\mathrm{CO}_{2}$ Laser System}

In order to generate the required marking pattern, specific software (Winmark software 2.1.0.3468; Synrad Inc., USA) to the laser was used. In addition, the software was capable of using images saved as .dxf files which can be produced by using CAD programs such as, in this case, Licom AutoCaM. The sample material was held in the system with a bracket on a variable z-axis stage and was positioned at the focal length, which was $250 \mathrm{~mm}$ from the laser aperture to the sample surface. The $10.6 \mu \mathrm{m}$ wavelength cw $10 \mathrm{~W} \mathrm{CO}_{2}$ laser system (Synrad Inc., USA), with a spot size of $100 \mu \mathrm{m}$, used a galvanometer scanner to scan the beam directly across the target material in conjunction with the pattern produced on the Synrad software. It should also be noted here that the target material and laser system was held in a laser safety cabinet in which the ambient gas was air. Additionally, an extraction system was used to remove any fumes produced during laser processing.

\section{2 $-F_{2}$ Excimer Laser System}

The $\mathrm{F}_{2}$ excimer laser system (LPF 202; Lambda Physik Inc., USA) operated at a wavelength of $157 \mathrm{~nm}$. The max pulse energy was $35 \mathrm{~mJ}$ and a pulse duration $\sim 11 \mathrm{~ns}$ (FWHM) at $26 \mathrm{kV}$ charging voltage. Samples were irradiated using a projection etching system, see Figure 1, and the lateral position of the samples were controlled using computerized stages with typically one micron resolution. The beam delivery system consisted of a $\sim 2$ meter long stainless steel beam tube between the laser and sample chamber which was evacuated to expel absorbing oxygen species. Experiments were carried out at pressure of around $2 \times 10^{-3}$ mbar. 
In order to achieve the required trench dimensions an aperture projection mask was produced using SS316 foil (Laser Micromachining Ltd., UK). The mask was $30 \times 30 \mathrm{~mm}^{2}$ and consisted of an array of five apertures with a diameter of $0.5 \mathrm{~mm}$ in a straight line spaced by $1 \mathrm{~mm}$ centre to centre. This allowed $50 \mu \mathrm{m}$ wide trenches to be etched, spaced by $50 \mu \mathrm{m}$ upon using a demagnification of 10 .

\section{3 - Laser Irradiation Procedures}

The nylon 6,6 was sourced in $100 \times 100 \mathrm{~mm}^{2}$ sheets with a thickness of $5 \mathrm{~mm}$ (Goodfellow Cambridge Ltd., UK). To obtain a conveniently sized sample for experimentation, the as-received nylon sheet was cut into $30 \mathrm{~mm}$ diameter discs using a $1 \mathrm{~kW} \mathrm{cw} \mathrm{CO}$ laser (Everlase S48; Coherent Ltd, UK). No discernible heat affected zone (HAZ) was observed under optical microscopic examination.

For the Synrad $\mathrm{CO}_{2}$ laser system, trenches were produced with a spacing of $50 \mu \mathrm{m}$ between each trench by scanning the beam across the target material. To produce these spaces, each experiment was carried out twice: firstly using a power of $50 \%(5 \mathrm{~W})$ with a velocity of $1000 \mathrm{mms}^{-1}$ and secondly using a power of $80 \%$ ( $8 \mathrm{~W}$ ) with the same velocity (sample $\mathrm{C} 10$ and C9, respectively). With powers of 5 and $8 \mathrm{~W}$ used and a spot size of $100 \mu \mathrm{m}$ the corresponding irradiances used for these experiments were 6.4 and 10.2 $\mathrm{kWcm}^{-2}$ respectively.

The $\mathrm{F}_{2}$ excimer laser system was used to produce two areas of etched trenches by traversing the stage and keeping the beam stationary. The first of these being to achieve an etch depth of approximately $1 \mu \mathrm{m}$ (sample F3) and the second giving a depth of approximately $10 \mu \mathrm{m}$ (sample F4). In order to achieve these depths each site required 1,000 and 10,000 pulses, respectively, as the etch depth per pulse was determined to be approximately $1 \mathrm{~nm}$ per pulse. With this in mind it was possible to determine the traverse velocities, $\mathrm{v}_{\mathrm{t}}$, by using Equation (1).

$$
v_{t}=\frac{D R}{N}
$$

Where $D$ is the diameter of one of the apertures in the mask, $R$ is the repetition rate (which was $20 \mathrm{~Hz}$ ) and $N$ is the number of pulses. Upon using this equation it was determined that for 1 and $10 \mu \mathrm{m}$ deep trenches velocities of 0.01 and $0.001 \mathrm{mms}^{-1}$ were to be used, respectively. It should be noted that the when carrying out the experiments using the $\mathrm{F}_{2}$ laser a constant fluence of $40 \mathrm{mJcm}^{-2}$ was used.

For comparison between the laser irradiated samples an as-received reference sample (N6) was also studied. This allowed any deviations from the original as-received characteristics to be identified after the laser processing had taken place. 


\section{4 - Mechanical Roughening Procedure}

For further verification of laser induced contact angle modification two samples were roughened manually using DA-F P220 emery paper. One sample was roughened using a zig-zag motion traversing from the top to the bottom of the sample (sample R1). The second sample (sample R2) was roughened by carrying out the same technique as the first sample, with the addition of rotating the sample through $90^{\circ}$ and repeating the roughening method with the emery paper.

\section{5 - Topography, Wettability Characteristics and Surface Chemistry Analysis}

After the laser irradiation of the nylon 6,6 samples they were analysed using a number of techniques. An optical microscope (Flash 200 Smartscope; OGP Ltd, UK) was used to obtain optical micrographs of the samples. The surface profiles were determined using a white light interferometer (WLI) (NewView 500; Zygo Ltd, USA) with MetroPro and TalyMap Gold Software. The Zygo WLI was setup using a $\times 10$ Mirau lens with a zoom of $\times 0.5$ and working distance of $7.6 \mathrm{~mm}$. This system also allowed Sa and Ra roughness parameters to be determined for each sample.

The samples were ultrasonically cleaned in isoproponal (Fisher Scientific Ltd., UK) for 3 minutes at room temperature before using a sessile drop device to determine various wettability characteristics, in accordance with the procedure detailed by Rance [26]. This was to allow for a relatively clean surface prior to any contact angle measurements being taken. A sessile drop device (OCA20; Dataphysics Instruments, GmbH) was used in conjunction with specific software (SCA20; Dataphysics Instruments, $\mathrm{GmbH})$ so that the recent advancing and receding contact angles for triply distilled water and the recent advancing angle for diodomethane could be determined for each sample. By achieving the advancing and receding contact angles the hysteresis for the system was determined. This was done by using the 'needle in' method to accurately add or remove liquid to give the advancing and receding liquid-solid-vapour line, respectively. In addition, by knowing the advancing contact angles for the two liquids it was possible to use the software to draw a Owens, Wendt, Rabel and Kaeble (OWRK) plot to determine the surface energy of the samples. For the two reference liquids the SCA20 software used the Ström et al. technique to calculate the surface energy of the material. It should be noted here that 10 contact angles, using 2 droplets, in each instance was recorded to achieve a mean contact angle for each liquid-surface interface.

Selected samples were analysed using X-ray photoelectron spectroscopy (XPS), were also sputter coated with $\mathrm{Au}$ to attain adequate conductance and analysed using scanning electron microscopy (SEM) and energy dispersive X-ray (EDX) analysis. This allowed any surface modifications in terms of chemical composition due to the laser irradiation to be revealed. 


\section{4 - Results and Discussion}

\section{1 - Optical Microscopy Analysis}

In order to effectively and completely compare the laser irradiated samples an optical micrograph of the as-received reference sample material was obtained, as can be seen in Figure 2.

The optical micrograph of the as-received reference sample shown in Figure 2 appears to have a minimal surface topography. The black dots on the image arise from the debris from the cutting of the samples and as such was removed during the ultrasonic cleaning process.

It was seen that both laser systems gave the ability to produce relatively good quality $\mu \mathrm{m}$ features on the nylon 6,6 samples. With regards to the trenches produced by the $\mathrm{CO}_{2}$ laser, with a distance of $50 \mu \mathrm{m}$ between each trench, it can be seen in Figure 3 that no distinct trench lines had been produced.

Even so, from Figure 3 it is possible to visualize that the $\mathrm{CO}_{2}$ beam was scanned horizontally across the sample. However, as the spot size of the $\mathrm{CO}_{2}$ laser was $100 \mu \mathrm{m}$ the scan overlapped itself so that no distinct periodic grooves were left in the material. In addition to this, gas bubble rupture sites can be seen on the surface which is considered to be as a result of the melting and re-solidification of the nylon 6,6 following $\mathrm{CO}_{2}$ laser processing. Also, as a consequence of the melting the material does not ablate with the $\mathrm{CO}_{2}$ laser and as the material re-solidifies it produces a protrusion away from the surface. In comparison, the $\mathrm{F}_{2}$ excimer laser produces grooves that were considerably better defined, as can be seen in Figure 4. One other major difference that the $F_{2}$ excimer laser offers is that the trenches were ablated and etched into the nylon 6,6 sample.

\section{2 - White Light Inteferometry Analysis}

The Zygo WLI and TalyMap Gold software were employed to elucidate the surface properties of the laser irradiated surfaces. Figure 5 shows the continuous axonometric and profile extraction of the as-received reference nylon 6,6 sample.

The continuous axonometric and profile extraction (see Figure 5) shows qualitatively how smooth the surface of the nylon 6,6 was prior to laser irradiation. In quantitive terms by utilizing the software the roughness parameters for the as-received reference sample were determined to be 0.038 and $0.043 \mu \mathrm{m}$ for $\mathrm{Sa}$ and $\mathrm{Ra}$, respectively. The profile extraction (see Figure 5) allowed one to see that maximum peak heights of the surface topography was up to $0.3 \mu \mathrm{m}$. In comparison, the $\mathrm{CO}_{2}$ laser irradiated samples were considerably rougher than the as-received reference sample indicating that considerable surface topography changes of nylon 6,6 were possible by utilizing this specific type of laser. Figures 6 and 7 
show continuous axonometric and profile extractions (perpendicular to the grooves) for the $\mathrm{CO}_{2}$ laser irradiated samples.

The surface roughness parameters, $\mathrm{Sa}$ and $\mathrm{Ra}$, were determined for each of the surfaces, all of which are given in Table 1. The Sa roughness values for the $5 \mathrm{~W} \mathrm{CO}_{2}$ laser irradiated nylon surface was found to be $0.262 \mu \mathrm{m}$, whereas the higher power of $8 \mathrm{~W}$ gave rise to a slightly rougher surface with an Sa value of $0.358 \mu \mathrm{m}$. In addition, the effect the beam had on the surface topography can be seen more prominently in Figures 6 and 7. However, by taking a profile extraction (see Figures 6 and 7) of the surfaces perpendicular to the direction of the grooves, it can be seen that there was slight periodicity to the surface pattern in comparison to the $F_{2}$ excimer laser patterned samples (see Figures 8 and 9). This is due to the fact that the $\mathrm{CO}_{2}$ laser spot size was larger than the intended surface pattern and the scanned beam overlapped during processing inherently eradicating the natural periodicity of the induced pattern. In addition, Figures 6 and 7 show that the maximum peak height observed for C10 and C9 were 2 and $3 \mu \mathrm{m}$ respectively, which is considerably larger then that of the as-received reference sample (N6). Even though there was little periodicity for the patterned samples shown in Figures 6 and 7, it can be seen that there were distinct grooves produced in the nylon 6,6 as a result of the $\mathrm{CO}_{2}$ laser processing. This is more discernible when comparing the continuous axonometric images (see Figures 6 and 7) with that of the asreceived reference sample shown in Figure 5, along with the relative profile extraction curves.

Figures 8 and 9 show the continuous axonometric images for the $F_{2}$ excimer laser irradiated nylon surfaces for different pulse numbers per site. The etched trenches using the $F_{2}$ excimer laser shown in Figures 8 and 9 were considerably more defined than the $\mathrm{CO}_{2}$ laser irradiated samples (see Figures 6 and 7). In comparison to the $\mathrm{CO}_{2}$ laser irradiated samples the pattern excimer etched into the sample had a more distinct periodicity and can be easily identified with the profile extractions as shown in Figures 8 and 9. The roughness parameter, Sa, for the surface (F3) was found to be $0.248 \mu \mathrm{m}$, whereas the roughness for F4 was found to be $2.647 \mu \mathrm{m}$ which was considerably greater than the other three samples due to the depth of the trenches being approximately $10 \mu \mathrm{m}$. It should be noted that for the other three samples the surface features were around 2 to $5 \mu \mathrm{m}$ as can be seen in the other profile extractions (Figures 6, 7, 8 and 9). In comparison with the as-received reference sample it can be seen that both lasers are capable of increasing the roughness of the surface of nylon 6,6; however, as the $F_{2}$ excimer laser offers better precision and accuracy due to the etch rate for this particular system being of the order of $1 \mathrm{~nm}$ per pulse it can be seen that the laser-induced topographical pattern can be more accurately controlled with the excimer laser. This is contrasted with the $\mathrm{CO}_{2}$ laser system as the surface pattern is dependant on the surface melting and resolidifying to produce protrusions out of the surface which gives rise to a noticeable level of inaccuracy for the surface topographical pattern. 


\section{3 - Effects of Laser Irradiation on the Wettability Characteristics}

As it has already been discussed, it is believed by many that the wettability of a material is the potential driving force in regards to the prediction of how a biomaterial will perform within a biological environment $[3,12,17]$. The dynamic advancing contact angles, hysteresis and surface energies for each of the samples can be seen in Table 1, along with the roughness parameters Sa, Ra for each sample.

For all of the laser surface patterned samples it can be seen from Table 1 that the surface roughness has been increased considerably in comparison to the as-received reference sample (N6). That is, the Ra and Sa increased by up to 2.9 and $2.6 \mu \mathrm{m}$, respectively. The largest roughness values were produced using the $\mathrm{F}_{2}$ excimer laser (samples F3 and F4) which can be owed to the fact that deeper trenches were induced compared with the features arising from using the $\mathrm{CO}_{2}$ laser marker (samples $\mathrm{C} 10$ and C9). It can also be seen from Table 1 that the contact angle for each laser patterned sample increased with the $\mathrm{F}_{2}$ excimer laser patterned samples giving the largest change with a contact angle of $72.92^{\circ}$ for the roughest sample (sample F4). This does not concur with current theory as the contact angle should decrease with increasing surface roughness for initially hydrophilic materials which have a contact angle less than $90^{\circ}$ prior to any modifications taking place [12,27]. After $\mathrm{CO}_{2}$ laser irradiation the apparent total surface energy, $\gamma^{\mathrm{T}}$, was slightly reduced due to a change in polar, $\gamma^{\mathrm{P}}$, and dispersive, $\gamma^{\mathrm{D}}$, components. It can be seen that the apparent $\gamma^{\mathrm{P}}$ increases by up to $4.12 \mathrm{mJm}^{-2}$ for the rougher sample (sample C9), whereas the $\gamma^{\mathrm{D}}$ was reduced at most by $12.22 \mathrm{mJm}^{-2}$. As it is $\gamma^{\mathrm{P}}$ of the surface energy that plays the major role in determining the contact angle it can be seen that these results also do not correspond with existing theory. For instance, Lawrence and $\mathrm{Li}$ [25] stated that a laser-induced increase in the $\gamma^{\mathrm{P}}$, along with an increase in $\mathrm{O}_{2}$ content, would give rise to a reduction in the contact angle. However, it has been seen that the apparent $\gamma^{\mathrm{T}}$ reduces for the $\mathrm{CO}_{2}$ laser patterned nylon 6,6 surfaces and this could correspond with current theory as it has previously been observed that the contact angle is inversely proportional to $\gamma^{\mathrm{T}}$ [28]. Following on, subsequent to $\mathrm{F}_{2}$ excimer laser patterning $\gamma^{\mathrm{T}}$ and $\gamma^{\mathrm{P}}$ was considerably reduce with $\gamma^{\mathrm{P}}$ reducing by up to $10 \mathrm{mJm}^{-2}$ (See Table 1). It is highly likely that this rise in contact angle can be attributed to the significant reduction of the apparent $\gamma^{T}$ resulting from an intermediate mixed state wetting regime arising from the topographical pattern induced onto the nylon 6,6 samples. This mixed state wetting regime was also hypothesized by Lee and Kwon who also observed an increase in contact angle for patterned topographies on a hydrophilic surface [10].

In order to determine if these changes in surface energies were as a result of variations in surface chemistry the samples where analysed using XPS and EDX. Table 1 shows the surface $\mathrm{O}_{2}$ content for all of the samples. The as-received reference sample showed that the surface $\mathrm{O}_{2}$ content was initially $11.90 \%$ 
At. (20.76\% for EDX). In comparison, for the $\mathrm{CO}_{2}$ laser patterned samples the oxygen content had risen slightly by up to $1.5 \%$ At. (2.03\% for EDX), whereas the $\mathrm{F}_{2}$ excimer laser patterned samples had less surface oxygen content with a reduction of up to $1.6 \%$ At. (4.42\% for EDX). The $\mathrm{O}_{2}$ in the ambient air of the $\mathrm{CO}_{2}$ system would have allowed oxidation of the surface to occur as the molten nylon re-solidified. Additionally, as the $F_{2}$ excimer laser system was under vacuum, there would have been a reduction in ambient air and as a result the surface would not oxidize and could potentially lose $\mathrm{O}_{2}$ content during the laser ablation process. From these results one can deduce that the effect of surface $\mathrm{O}_{2}$ content is not conclusive and as such it can be seen that it is more likely that the mixed state wetting regime owed to the induced topographical patterns are the dominating factor in this instance. It should also be noted that the XPS data showed no other significant amounts of other elements present before or after the laser processing, other than carbon and oxygen which are the main constituents of nylon 6,6.

To clarify how the laser induced patterns effected changes in the characteristic contact angle, two samples were mechanically roughened using emery paper, of which the continuous axonometric images can be seen in Figure 10 and 11. As a result of the mechanical roughening of the samples it can be seen in Table 1 that an increase in apparent polar component and roughness has given rise to a significant reduction in contact angle, which agrees with Lawrence and Li [25]; that is, the apparent polar component increased by up to $4.53 \mathrm{mJm}^{-2}$ and a considerable increase in surface roughness of up to 100 times that of the asreceived reference sample was observed for samples R1 and R2. Also, as given in Table 1 the surface $\mathrm{O}_{2}$ content for the manually roughened samples was somewhat unchanged in comparison to the as-received reference sample, highlighting that the surface roughness, surface energy and topographical pattern have more of an impact on the wettability characteristics. This finding can be seen to be of significance as even though there was a considerable increase in surface roughness the manually roughened samples (see Figures 10 and 11) gave an indication that no periodic pattern was induced on the surface of the nylon 6,6 samples. In contrast, the laser patterned samples had more periodic patterns relative to the manually roughened surfaces and from this it can be seen that the periodic patterns had an extremely large affect on the wettability of the samples. As discussed by Jung and Bhushan [29] there are two regimes in which a material can wet: the Cassie-Baxter and Wenzel regimes. The Wenzel regime, shown in Figure 12, allows the whole sample to be wetted such that the droplet is in complete contact with the surface. On the other hand, the Cassie-Baxter regime, shown in Figure 13, allows the droplet to rest upon the roughened surface peaks forming air gaps between the droplet and the surface.

It is proposed here that a change from the Wenzel regime to a mixed state wetting regime was the likely reason for the observed increase in the contact angle for the $\mathrm{CO}_{2}$ laser and $\mathrm{F}_{2}$ excimer laser patterned nylon 6,6 in accordance with work carried out by others [10,30-32]. That is the liquid, when in contact 
with the sample surface, gives rise to a mixture of Wenzel and Cassie-Baxter regimes. This can be an explanation as to how an increase in contact angle was observed for the laser patterned samples and still be hydrophilic. Therefore, it has been seen in this instance that the topographical surface pattern appears to be the main driver for the manipulation of the wettability characteristics.

Due to the ability of using these laser systems to manipulate the wettability characteristics further research can be carried out by undertaking biological testing of the laser patterned samples. This would determine if cell adhesion and proliferation can be optimized by using these lasers to produce surface modification in terms of surface chemistry and surface topography. In addition, as nylon 6,6 has a high water absorption rate it may be possible to identify, through extended research, whether surface modifications using laser technology allows this parameter to be reduced. By experimenting with different ambient gases it may also be possible to inflict greater chemical changes on the surface of the material allowing for further studies of how the chemical nature of the surface gives rise to the variation in contact angle and surface energy.

\section{5 - Conclusions}

It has been demonstrated that both the $\mathrm{CO}_{2}$ and $\mathrm{F}_{2}$ excimer laser systems that have been employed in this study have the ability to modify the surface of nylon 6,6 . The $\mathrm{CO}_{2}$ laser couples into the material via resonant coupling which gives rise to bond vibrations allowing the temperature to rise and melt the material. Upon cooling the molten material re-solidifies and a protrusion away from the surface becomes evident on the surface. This is contrasted with the $\mathrm{F}_{2}$ excimer laser as it ablates the nylon 6,6 allowing the required pattern to be etched into the material. As a result the $F_{2}$ excimer laser system offers a major advantage over the $\mathrm{CO}_{2}$ in the fact that it ablates approximately $1 \mathrm{~nm}$ per pulse, with the fluence used in this instance, allowing the user to be more precise and accurate with the surface topography they require. However, the amount of time it takes to pump the $\mathrm{F}_{2}$ vacuum system to operating pressure and the amount of time it takes to produce a number of few $\mu \mathrm{m}$ deep trenches is considerably greater than the $\mathrm{CO}_{2}$ laser system employed in this study.

Both of the laser systems affect differently the nylon 6,6 samples with regards to wettability and surface energy parameters - two major factors which are believed to manipulate the bioactivity of a material in regards to cell adhesion and proliferation. The $\mathrm{CO}_{2}$ laser has been seen to be capable of producing contact angles slightly larger in comparison to the as-received reference sample In this instance, as a result of the $\mathrm{CO}_{2}$ laser patterning the surface $\mathrm{O}_{2}$ content increased by up to $1.5 \%$ At. and the apparent polar component also increased by up to $4.12 \mathrm{mJm}^{-2}$. This does not agree with current theory as an increase in apparent polar component and surface $\mathrm{O}_{2}$ content should give rise to a reduction in contact angle. In contrast, for 
the $\mathrm{F}_{2}$ excimer laser patterned samples the apparent polar component and surface $\mathrm{O}_{2}$ content decreased by up to $11.69 \mathrm{mJm}^{-2}$ and $1.6 \%$ At., respectively. It has been proposed here that the increase in contact angle resulting from the laser modifications is due to the patterned topographies, such that they give rise to a intermediate mixed state wetting regime in which both Wenzel and Cassie-Baxter regimes arise. This allows one to see how the $\mathrm{CO}_{2}$ laser irradiated samples would give a larger contact angle in comparison to the as-received reference sample. To aid in clarification, manually roughened samples were analysed which showed that for a non-periodic rough surface the apparent polar component increased and surface $\mathrm{O}_{2}$ content remained somewhat unchanged giving rise to a reduction in contact angle. Significantly, this shows that the surface pattern dominates the wettability characteristics for the laser induced patterned nylon 6,6 samples.

\section{6 - Acknowledgements}

We would like to thank Directed Light Inc., East Midlands NHS Innovation Hub, Nobel Biocare and Photomachining Inc. for all of their much appreciated support. This study is financially supported by the EPSRC (No. EP/E046851/1).

\section{7 - References}

1. W. Pfleging, M. Bruns, A. Welle, S. Wilson, Laser-assisted modification of polystyrene surfaces for cell culture applications, Appl. Surf. Sci. 253 (2007) 9177-9184.

2. K.S. The, Y. W. Lu, Topography and wettability control in biocompatible polymer for BioMEMs applications. Proceedings of the 3rd IEEE Int. Conf. on Nano/Micro Engineered and Molecular Systems, Sanya, China 2008.

3. M. S. Kim, G. Khang, H. B. Lee, Gradient polymer surfaces for biomedical applications. Prog. Polym. Sci. 2007.

4. M. D. Ball, R. Sherlock, T. Glynn, Cell interactions with laser-modified polymer surfaces, J. Mater. Sci.: Mater. Med. 15 (2004) 447-449.

5. Q. Zhao, C. Wang, Y. Liu, S. Wang, Bacterial adhesion on the metal-polymer composite coatings, Int. J. Adhes. Adhes. 27 (2007) 85-91.

6. E. M. Harnett, J. Alderman, T. Wood, The surface energy of various biomaterials coated with adhesion molecules used in cell culture, Colloids Surf., B 55 (2007) 90-97.

7. Y. C. Jung, B. Bhushan, Contact angle, adhesion and friction properties of micro- and nanopatterned polymers for superhydrophobicity, Nanotechnol. 17 (2006) 4970-4980.

8. M. Ouhlal, R. Xu, H. P. Schreiber, Adhesion enhancement through control of acid-base interactions, J. Adhes. 80 (2004) 467-480. 
9. E. Speranza, G. Gottardi, C. Pederzolli, L. Lunelli, R. Canteri, L. Pasquardini, Role of chemical interactions in bacterial adhesion to polymer surfaces, Biomaterials 25 (2004) 2029-2037.

10. S. M. Lee, T. H. Kwon, Effects of intrinsic hydrophobicity on wettability of polymer replicas of a superhydrophobic lotus leaf, J. Micromech. Microeng. 17 (2007) 687-692.

11. D. G. Waugh, J. Lawrence, Wettability characteristics variation of nylon 6,6 by means of $\mathrm{CO}_{2}$ laser generated surface patterns, ICALEO 2008 Proceedings 101 (2008) 61-69.

12. L. Hao, J. Lawrence, Laser surface treatment of bio-implant materials, John Wiley \& Sons Inc., New Jersey, USA, 2005.

13. R. S. Benson, Use of radiation in biomaterials science, Nucl. Instrum. Methods Phys. Res., Sect. B 191 (2002) 752-757.

14. F. Arefi-Khonsari, M. Tatouliana, F. Bretagnol, O. Bouloussa, F. Ronadlez, Processing of polymers by plasma technologies, Surf. Coat. Technol. 200 (2005) 14-20.

15. D. Pappas, A. Bujanda, J. D. Demaree, J. K. Hirvonen, W. Kosik, R. Jensen, S. McKnight, Surface modification of polyamide fibers and films using atmospheric plasmas, Surf. Coat. Technol. 201 (2006) 4384-4388.

16. F. Yu, L. Ping, H. Shen, S. Mather, C. M. Lehr, Laser interference lithography as a new and efficient technique for micropatterning of biopolymer surface, Biomaterials, 26 (2005) 2307-2312.

17. H. Mirzadeh, M. Dadsetan, Influence of laser surface modifying of polyethylene terephthalate on fibroblast cell adhesion, Radiat. Phys. Chem. 67 (2003) 381-385 .

18. C. D. Skordoulis, M. Makropoulou, A. A. Serafetinides, Ablation of nylon-6,6 with UV and IR lasers, Appl. Surf. Sci. 86 (1995) 239-244.

19. K. S. Tiaw, M. H. Hong, S. H. Teoh, Precision laser micro-processing of polymers. J. Alloys Compd. 2007.

20. E. Sarantopoulou, Polymer Self-Assembled Nano-Structures and Surface Relief Gratings Induced with Laser at 157nm, Appl. Surf. Sci. 253 (2007) 7884-7889.

21. T. O. Yoon, H. J. Shin, S. C. Jeoung, Y. I. Park, Formation of superhydrophobic poly(dimethysiloxane) by ultrafast laser-induced surface modification, Optics Express 16 (2008) 1271512725 .

22. V. Zorba, E. Stratakis, M. Barberooglou, E. Spanakis, P. Tzanetakis, S. H. Anastasiadis, C. Fotakis, Biomimetic artificial surfaces quantitatively reproduce the water repellency of a lotus leaf, Adv. Mater. 20 (2008) 4049-4054.

23. A. M. Kietzig, S. G. Hatzikiriakos, P. Englezos, Patterned superhydrophobic metallic surfaces, Langmuir 25 (2009) 4821-4827. 
24. Z. Ma, Z. Mao, C. Gao, Surface modification and property analysis of biomedical polymers used for tissue engineering, Colloids Surf., B 60 (2007) 137-157.

25. J. Lawrence, L. Li, Modification of the wettability characteristics of polymethyl methacrylate (PMMA) by means of $\mathrm{CO}_{2}, \mathrm{Nd}$ :YAG, excimer and high power diode laser irradiation, Mater. Sci. Eng., A 303 (2001) 142-149.

26. D. G. Rance, Chapter 6 - thermodynamics of wetting: From its molecular basis to technological application, in: D. M. Brewis (Ed.) Surface Analysis and Pretreatment of Plastics and Metals, Applied Science Publishers, Essex, UK, 1982, pp. 121.

27. J. Lawrence, L. Li, Laser modification of the wettability characteristics of engineering materials, Professional Engineering Publishing Limited, Suffolk, UK, 2001.

28. D. G. Waugh, J. Lawrence, C. L. Thomas, $\mathrm{CO}_{2}$ laser generated surface patterns and the effects thereof on the biomimetics and wettability of nylon 6,6. Submitted May 2009 Mater. Sci. Eng., C.

29. Y. C. Jung, B. Bhushan, Wetting transition of water droplets on superhydrophobic patterned surfaces, Scr. Mater. 57 (2007) 1057-1060.

30. Y. T. Cheng, D. E. Rodak, Is the lotus leaf superhydrophobic? Appl. Phys. Lett. 86 (2005) 144101-1244101-3

31. X.Chen, T. Lu, The apparent state of droplets on a rough surface, Sci. China Ser. G-Phys. Mech. Astron. 52 (2009) 233-238.

32. X. Wu, L. Zheng, D. Wu, Fabrication of superhydrophobic surfaces from microstructured ZnO-based surfaces via a wet-chemical route, Langmuir 21 (2005) 2665-2667. 


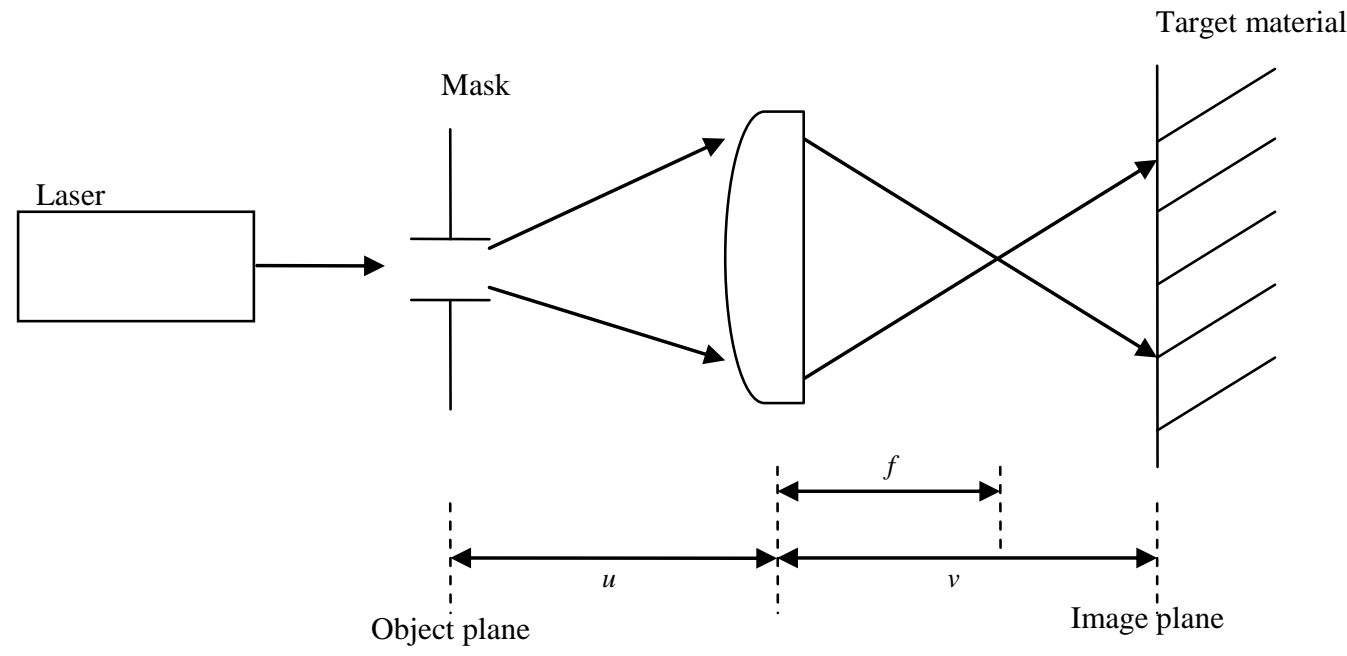

Figure 1 - Schematic diagram showing the projection etching system used with $u$ being the object distance, $v$ being the image distance and $\mathrm{f}$ the focal length of the lens. 


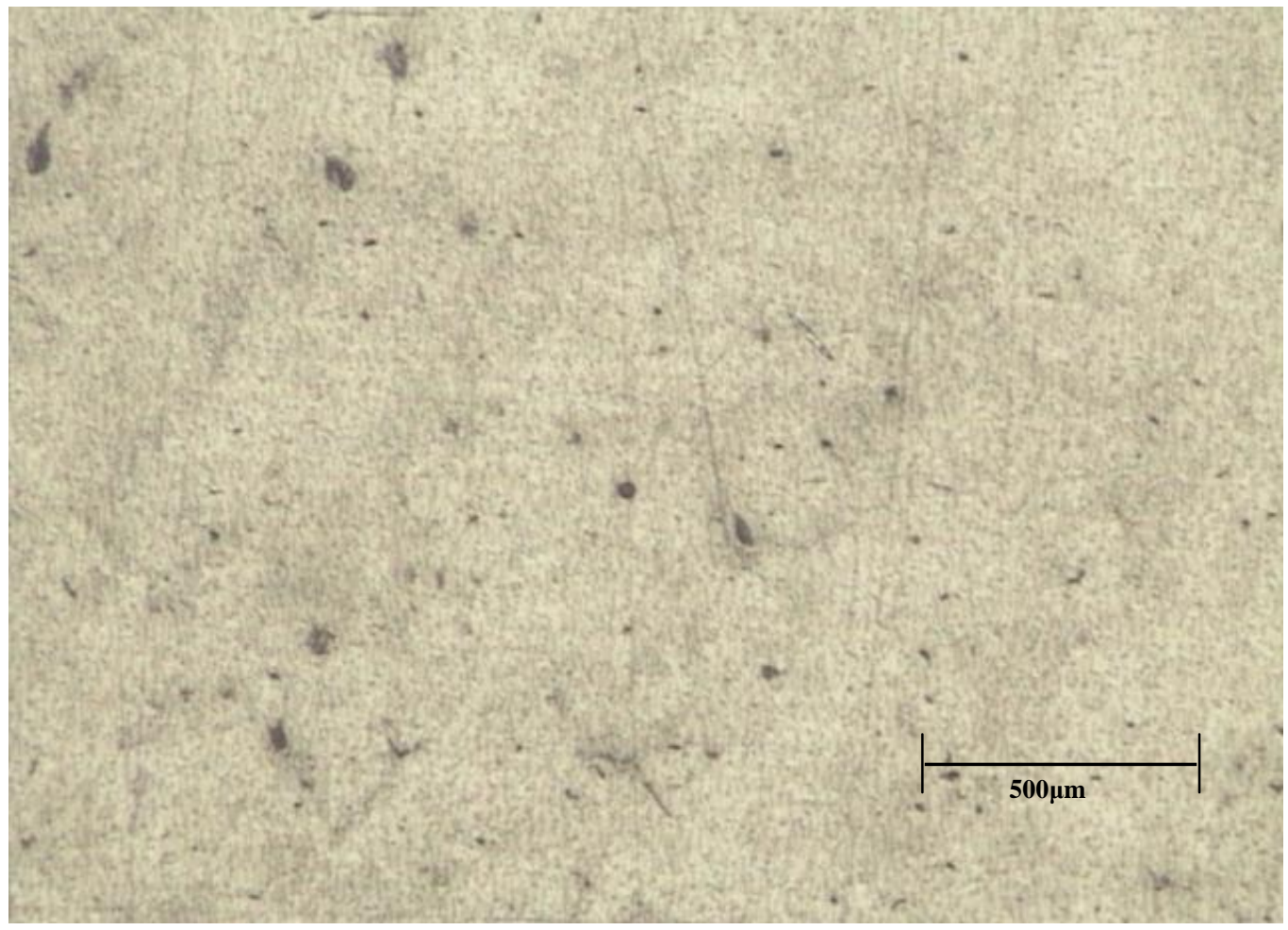

Figure 2 - Optical micrograph of the as-received reference nylon 6,6 sample (Sample N6). 


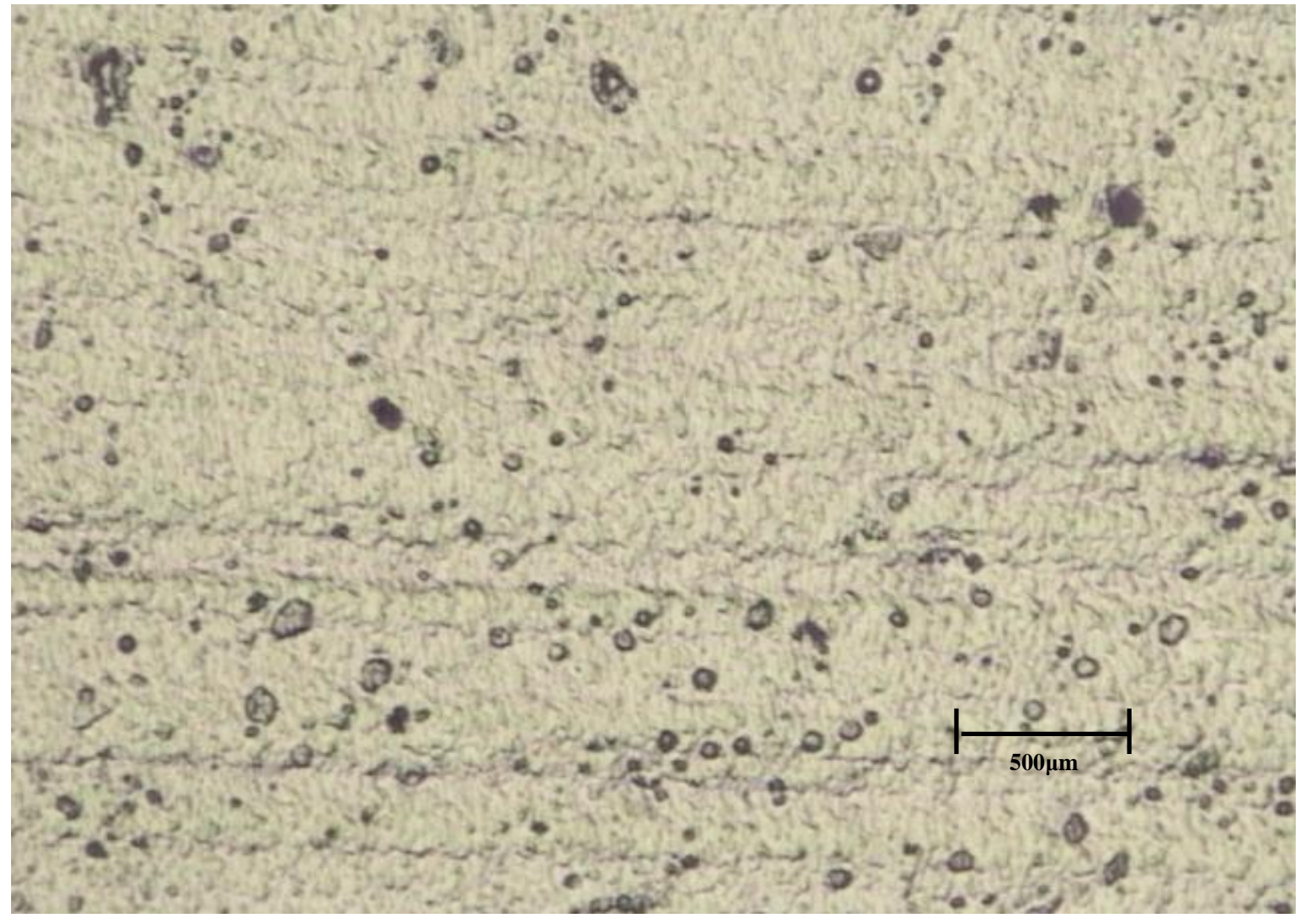

Figure 3 - Optical micrograph of nylon 6,6 $\mathrm{CO}_{2}$ laser irradiated sample using $8 \mathrm{~W}\left(10.2 \mathrm{kWcm}^{-2}\right), 1000$ $\mathrm{mms}^{-1}$ (Sample C9). 


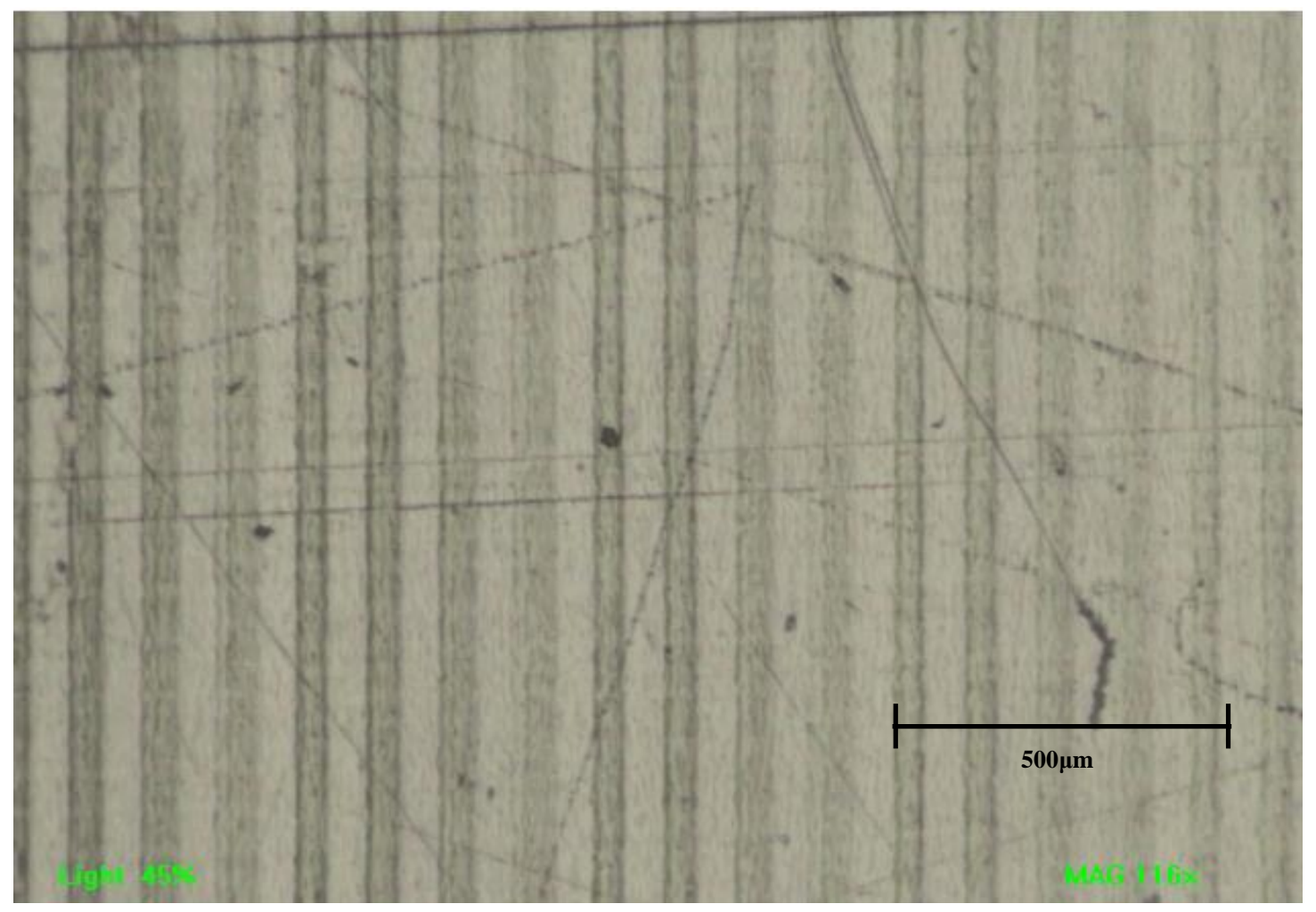

Figure 4 - Optical micrograph of trenches produced using the $F_{2}$ excimer laser using 1000 pulses per site, a fluence of $40 \mathrm{mJcm}^{-2}$ and a repetition rate of $20 \mathrm{~Hz}$ (Sample F3). 

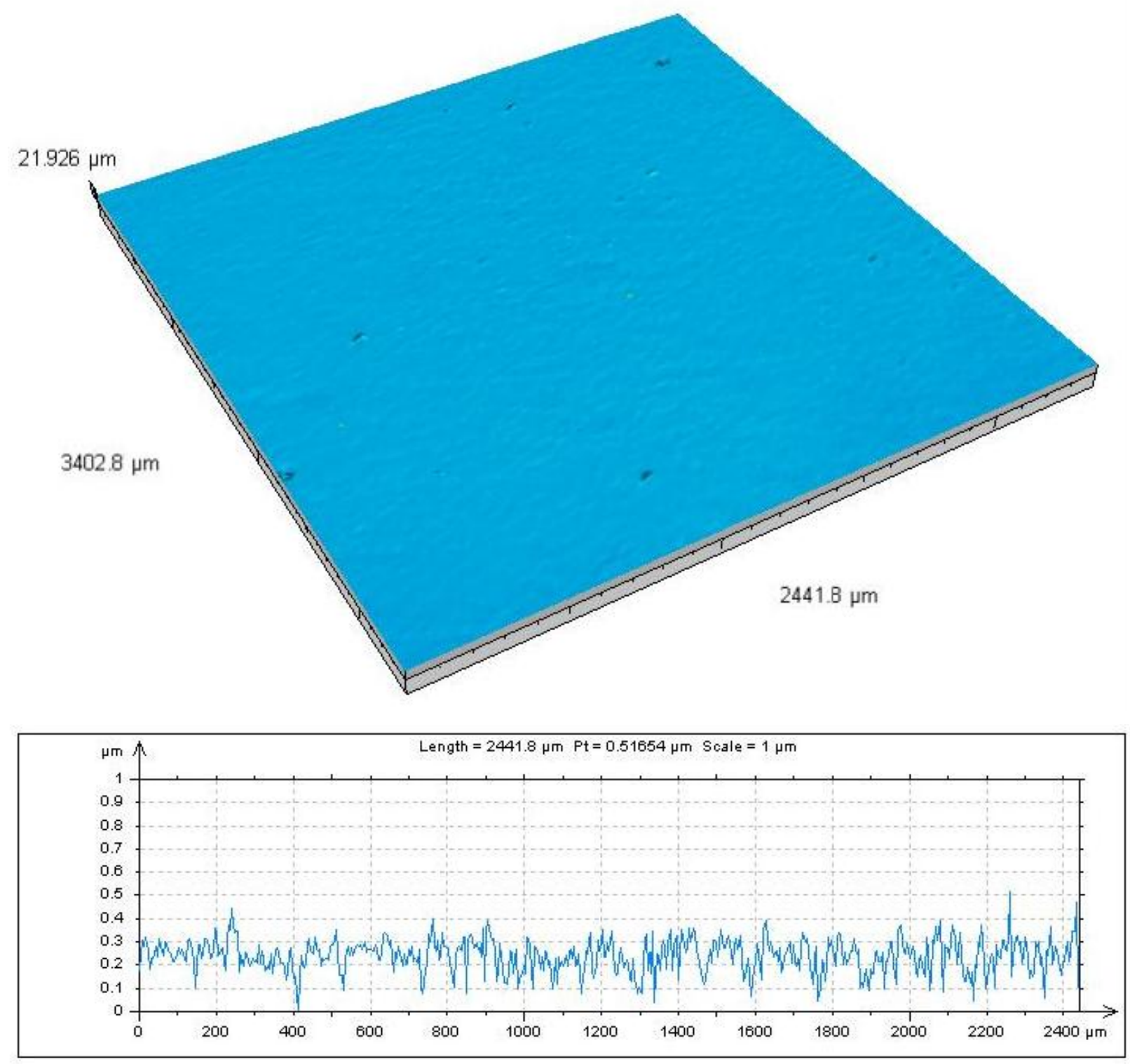

Figure 5 -Continuous axonometric and profile extraction for the as-received reference sample. (Sample N6) 

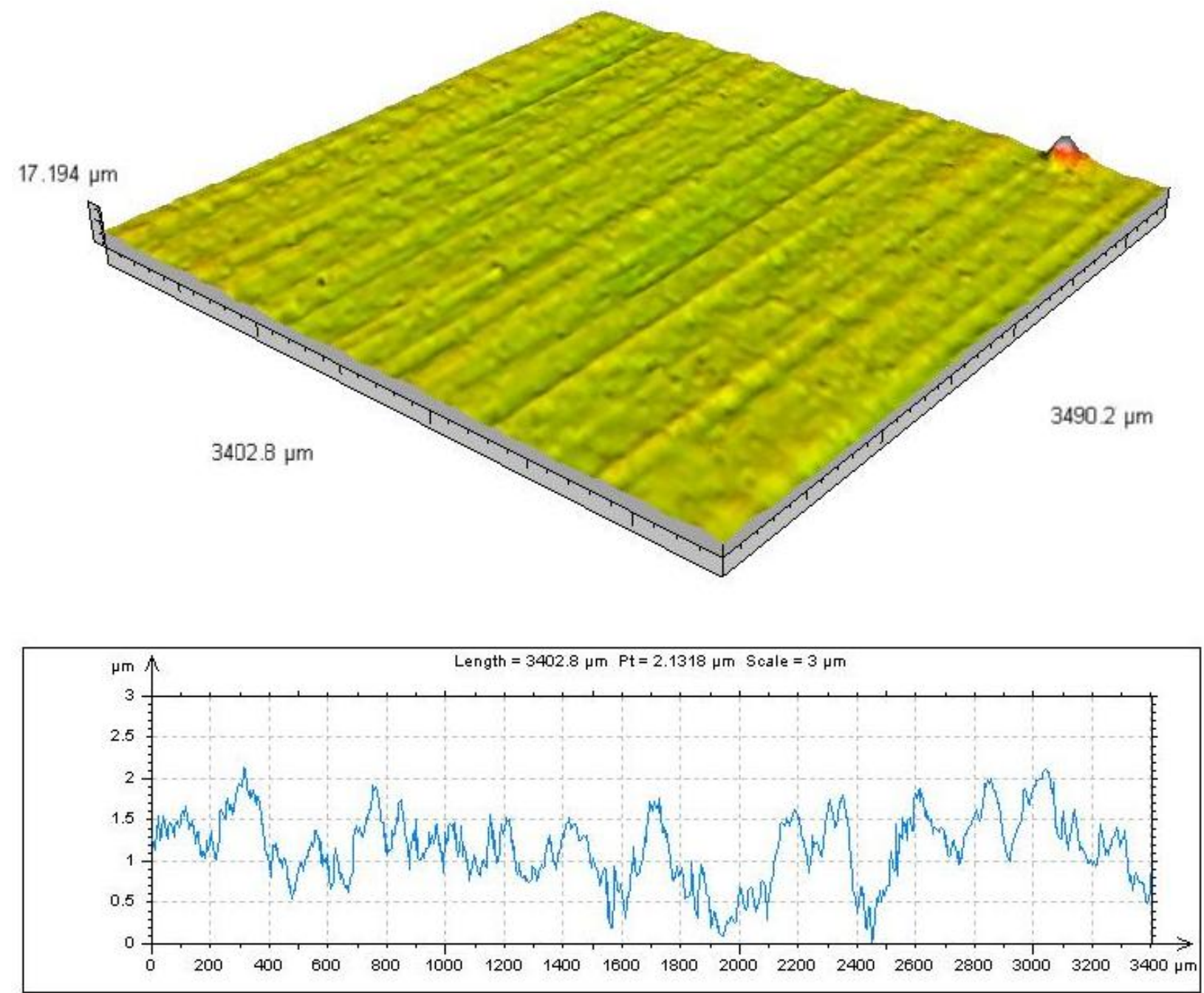

Figure 6 - Continuous axonometric and profile extraction for $\mathrm{CO}_{2}$ laser irradiated nylon 6,6 at $5 \mathrm{~W}(6.4$ $\mathrm{kWcm}^{-2}$ ), $1000 \mathrm{mms}^{-1}$ (Sample C10). 

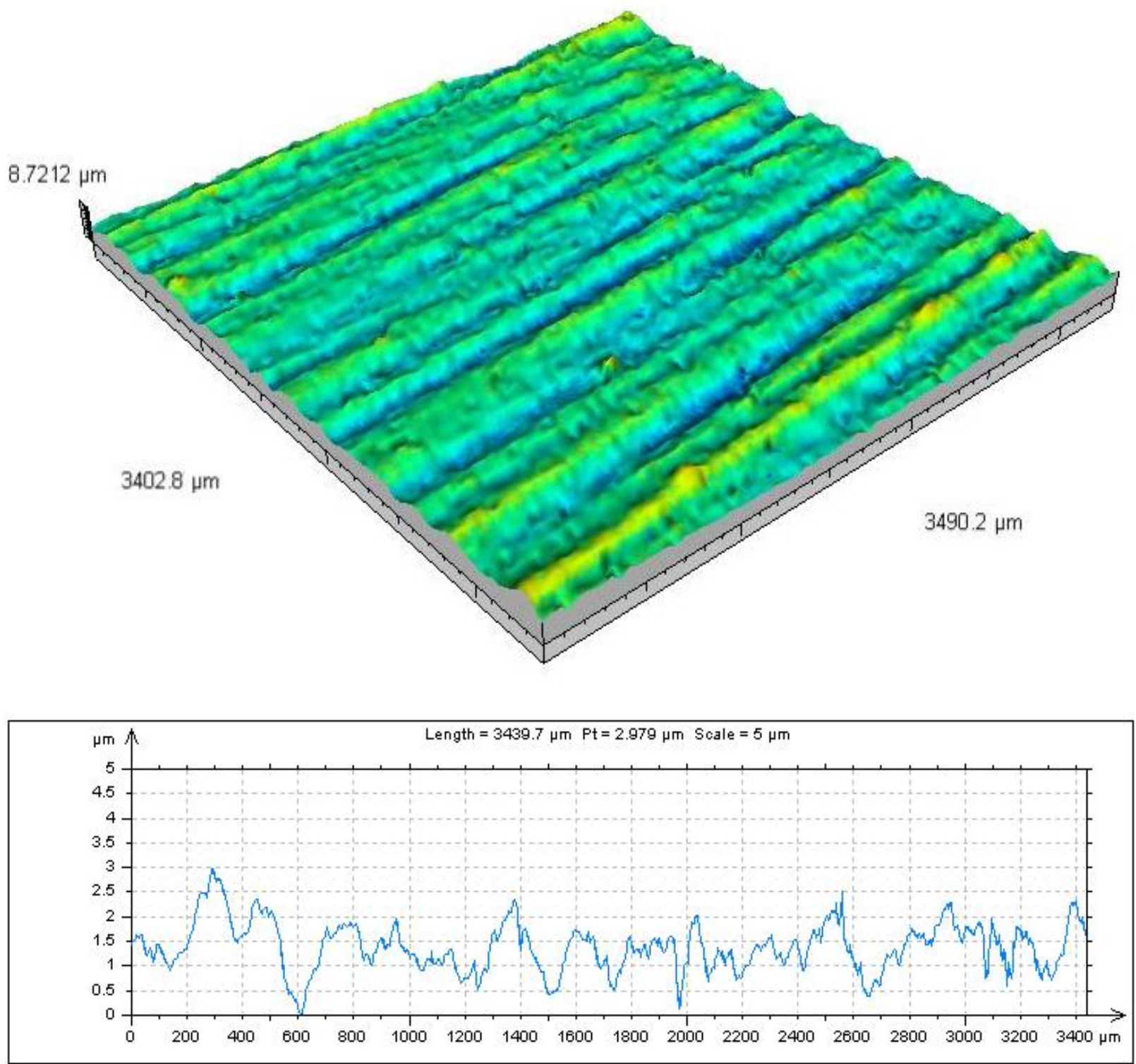

Figure 7 - Continuous axonometric and profile extraction for $\mathrm{CO}_{2}$ laser irradiated nylon 6,6 at $8 \mathrm{~W}(10.2$ $\mathrm{kWcm}^{-2}$ ), $1000 \mathrm{mms}^{-1}$ (Sample C9). 

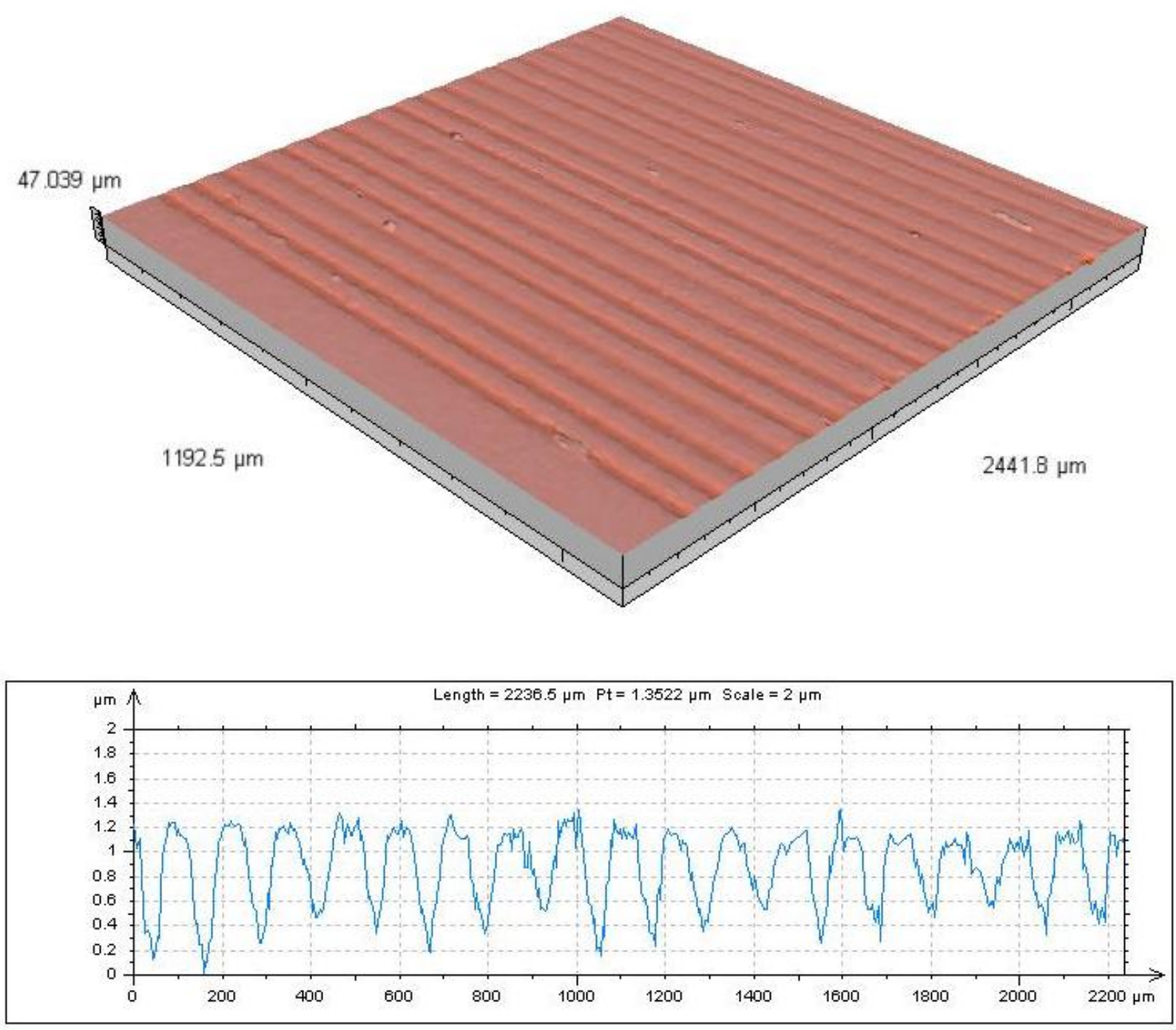

Figure 8 - Continuous axonometric and profile extraction for $\mathrm{F}_{2}$ excimer laser irradiated nylon 6,6 at 40 $\mathrm{mJcm}^{-2}$ and 1,000 pulses per site (Sample F3). 

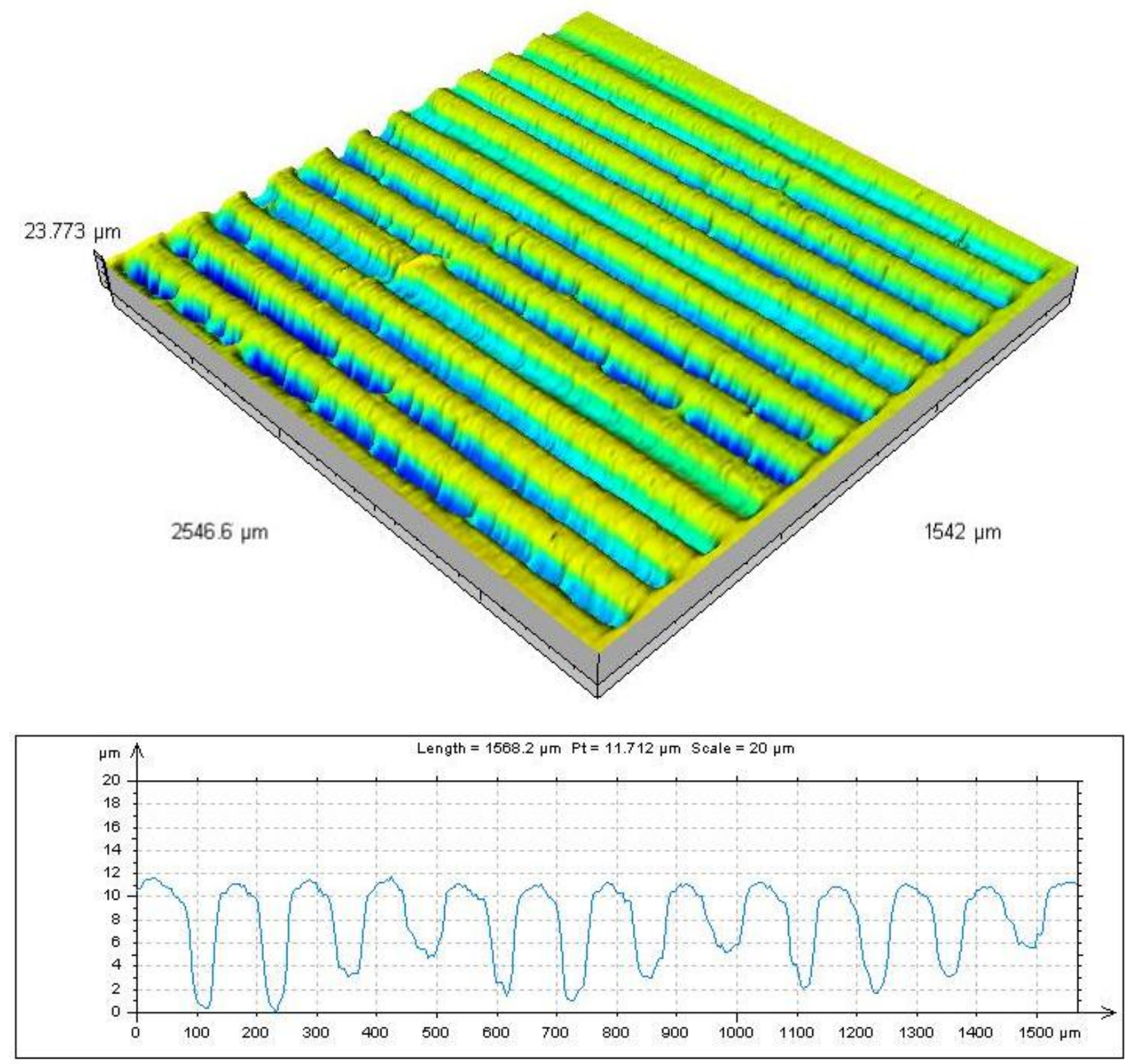

Figure 9 - Continuous axonometric and profile extraction for $\mathrm{F}_{2}$ excimer laser irradiated nylon 6,6 at 40 $\mathrm{mJcm}^{-2}$ and 10,000 pulses per site (Sample F4). 

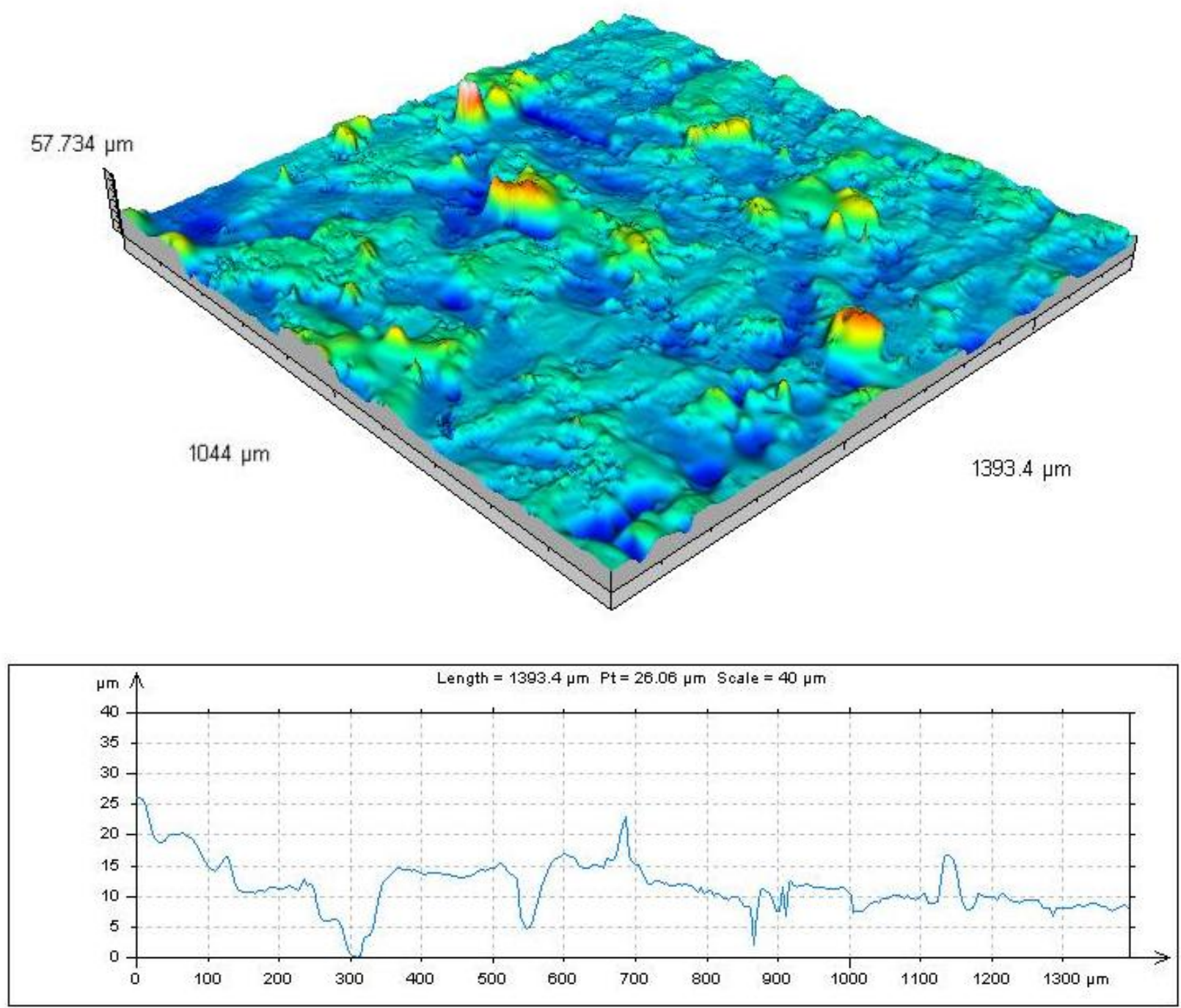

Figure 10 - Continuous axonometric and profile extraction of the first emery paper roughened sample (Sample R1). 

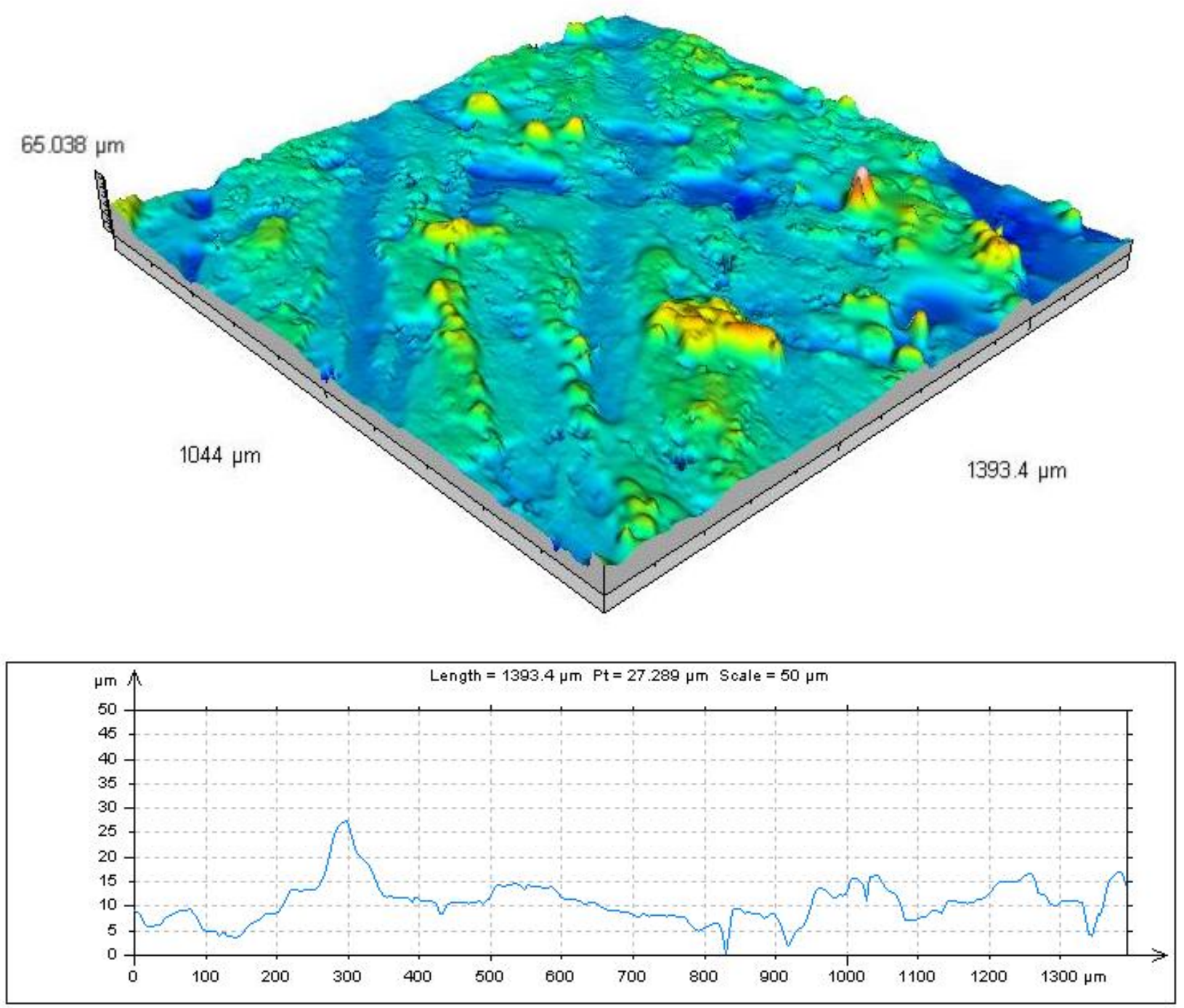

Figure 11 - Continuous axonometric and profile extraction of the second emery paper roughened sample (Sample R2). 


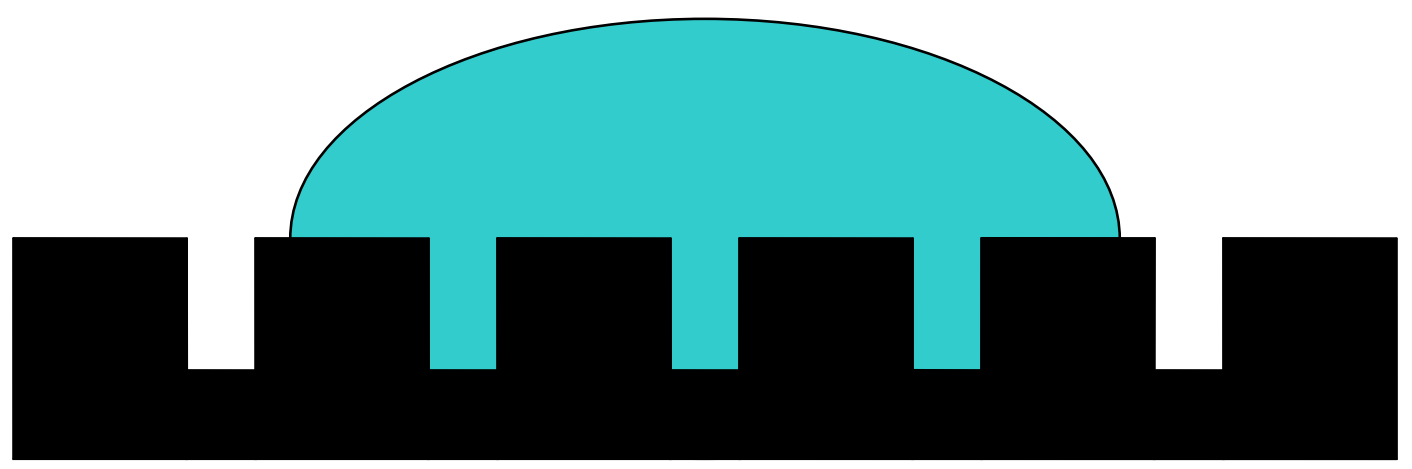

Figure 12 - Schematic diagram showing a droplet of water on a patterned surface giving rise to the Wenzel wetting regime. 


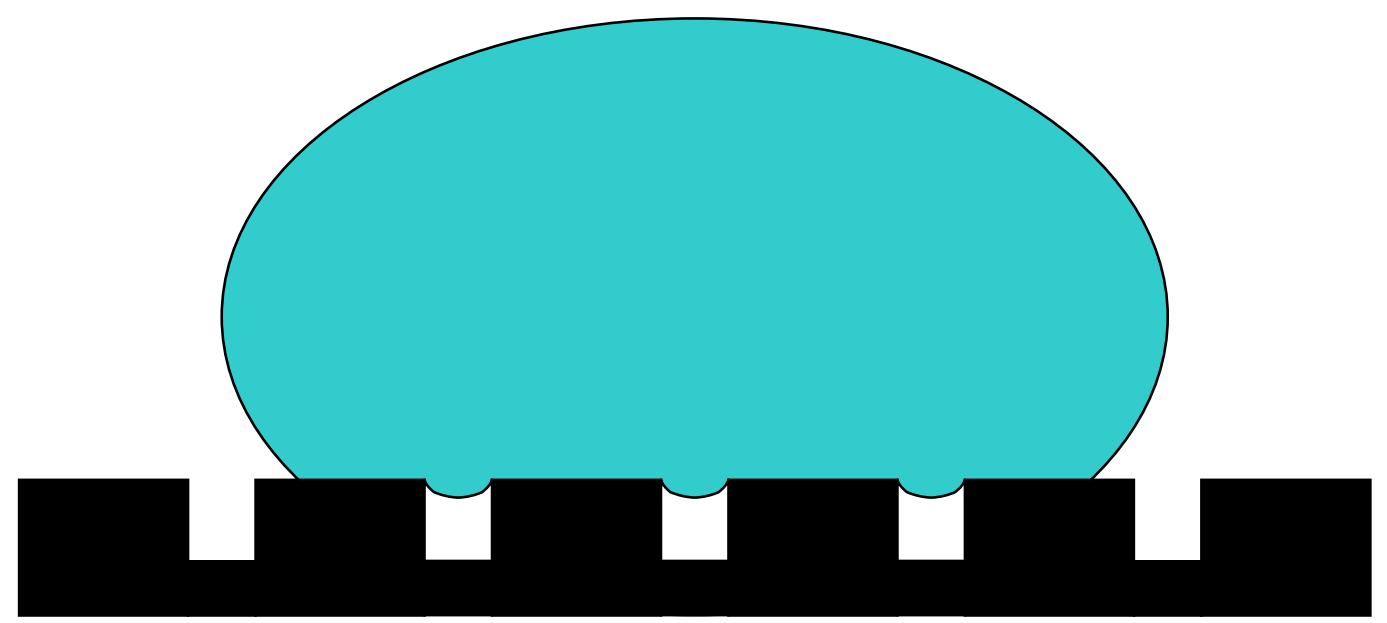

Figure 13 - Schematic diagram showing a droplet of water on a patterned surface giving rise to the Cassie-Baxter wetting regime. 
Table 1 - A summary of the results for the seven samples along with their characteristic contact angle and hysteresis with triply distilled water.

\begin{tabular}{|c|c|c|c|c|c|c|c|c|}
\hline $\begin{array}{c}\text { Sample } \\
\text { ID }\end{array}$ & $\begin{array}{c}\mathrm{Sa} \\
(\mu \mathrm{m})\end{array}$ & $\begin{array}{c}\mathrm{Ra} \\
(\mu \mathrm{m})\end{array}$ & $\begin{array}{c}\gamma^{\mathrm{P}} \\
\left(\mathrm{mJm}^{-2}\right)\end{array}$ & $\left(\mathrm{mJm}^{-2}\right)$ & $\left(\mathrm{mJm}^{-2}\right)$ & $\begin{array}{c}\text { Surface } \mathrm{O}_{2} \\
\text { Content } \\
(\%) /(\% \text { At. })\end{array}$ & $\begin{array}{c}\text { Contact } \\
\text { Angle } \\
\left(^{\circ}\right)\end{array}$ & Hysteresis \\
\hline \multicolumn{9}{|c|}{ As-Received Reference Sample } \\
\hline N6 & 0.038 & 0.043 & 20.15 & 36.12 & 56.27 & $20.76 / 11.90$ & 49.34 & 19.98 \\
\hline \multicolumn{9}{|c|}{$\mathrm{CO}_{2}$ Laser Surface Patterned Samples } \\
\hline $\mathrm{C} 10$ & 0.262 & 0.346 & 20.75 & 27.38 & 48.13 & $22.23 / 12.60$ & 53.91 & 17.22 \\
\hline C9 & 0.358 & 0.256 & 24.27 & 23.90 & 48.17 & $22.79 / 13.20$ & 52.36 & 19.82 \\
\hline \multicolumn{9}{|c|}{$\mathrm{F}_{2}$ Excimer Laser Surface Patterned Samples } \\
\hline F3 & 0.248 & 0.253 & 9.78 & 37.19 & 46.98 & $17.48 / 10.80$ & 66.67 & 31.05 \\
\hline F4 & 2.647 & 2.947 & 8.46 & 28.44 & 36.90 & $16.34 / 10.30$ & 72.92 & 40.97 \\
\hline \multicolumn{9}{|c|}{ Manually Roughened Samples } \\
\hline R1 & 3.104 & 2.368 & 22.57 & 34.86 & 57.43 & $20.70 / 11.60$ & 43.95 & 26.01 \\
\hline R2 & 3.735 & 3.055 & 24.68 & 36.85 & 61.53 & $20.72 / 11.70$ & 38.37 & 22.25 \\
\hline
\end{tabular}

